\title{
Impact of Educational Intervention on Reducing Postpartum Sleeping Pattern Alterations
}

\author{
Fatma B. Hassan ${ }^{1}$, Abd_El aziz G. Al- Darwish ${ }^{2}$, Entisar M. Youness ${ }^{3}$. \\ Nursing Specialist in Al Azhar Assiut University Hospita, Egypt. \\ Professor of Department of Obstetrics and Gynecology, Faculty of Medicine, Al Azhar Assiut University, Egypt. \\ Professor of Department of Obstetrics and Gynecological Nursing, Faculty of Nursing, Assiut University, Egypt
}

\begin{abstract}
Background: Most women (78\%) reported their sleep quality to be worse during the childbearing period than in any other time of their lives. Postpartum sleep disturbances are caused by the natural physiological alterations that follow childbirth. Aim: Is to assess the sleeping quality index among postpartum mothers and to determine the impact of educational intervention on improvement of postpartum sleeping pattern alterations. Design: Randomized control trial design. Sample: Consisted of (550) women immediately after delivery and divided into two main groups 275 for each. Study group received educational intervention booklet about good sleeping pattern and followed at $15^{\text {th }}$ day and after $42^{\text {nd }}$ day postpartum at Al Azhar Assiut University Hospital. The second group received the routine hospital care. Tools: Socio demographic data, the current delivery outcomes and Pittsburgh Sleep Quality Index, 2016 questionnaire. Results: About two thirds (65.8\%) of the study group had moderate sleep quality Vs. (69.8\%) of the control group with no statistical significant difference between both groups immediately after delivery. While there are highly statistical significant difference between both groups after $15^{\text {th }}$ days and after $42^{\text {nd }}$ days postpartum $(\mathrm{P}=0.000)$, for sleep quality items. Conclusion: Maternal sleep quality improved after 15 day and 42 day postpartum after implementing sleeping educational intervention. Recommendations: Further efforts are needed through educational intervention programs by nurses to improve maternal sleeping quality during pregnancy and the postpartum period.
\end{abstract}

\section{Key words: Pregnancy, Postpartum, Sleep, Sleep Disorder \& Sleep Hygiene.}

\section{Introduction}

Pregnancy and the postpartum period are recognized as times of vulnerability to psychiatric disorders, including mood, anxiety and psychotic disorders. The causes of these conditions are far from clear, although numerous hypotheses have been put forward. Many of these focus on the dramatic changes in peripheral concentrations of sex steroids that occur during pregnancy and in the immediate postpartum period ( Lee, 2016).Others draw attention to the predictive power of non- biologic variables, such as lack of social support, marital or relationship conflict, and the stress of child care (Robert et al., 2014).

For a long time, sleep was considered a kind of wasted time, which served only to restore the energy expended during the day. This view began to change in the first half of the twentieth century, but it was only in the last ten years, with advances in studies of genetics, molecular biology and neurochemistry, that most doctors had their attention drawn to the physiology and the real role of night rest in order to preserve health (Journal of nursing, 2012). Adequate sleep and rest are essential for postpartum women so they can meet the demanding needs of their newborns; however, impaired sleep, such as less nighttime sleep and more wake time after sleep onset, is prevalent in childbearing mothers with a healthy newborn baby (Gay et al., 2012) .
Physiologic changes that occur during pregnancy may have significant influences on sleep after birth. For example, throughout pregnancy cortisol, estrogen, and progesterone levels increase: high cortisol is associated with stress and depressive symptoms; high estrogen is associated with less Rapid eye movement sleep (REM sleep), fewer night waking, longer sleep times, and a decrease in sleep latency; and progesterone has a sedative effect and is known to increase Non-rapid eye movement sleep (non-REM sleep) (Manber \& Armitage, 2013). Postpartum sleep disturbances are also caused by the natural physiological alterations that follow childbirth. In a study where mothers slept away from their infants, maternal sleep disruption continued, which may have been due to physiological factors such as various hormonal regulations (Karacan et al., 2013).

The sleep patterns of new mothers are characterized by shorter sleep durations at night resulting in daytime fatigue (Goyal et al., 2012) This is particularly marked for first time mothers, who have lower sleep efficiency, spend more time in bed and have a greater wake after sleep onset during pregnancy than multiparous mothers (Waters \& Lee, 2012) These mothers also have fewer sleep episodes in the early postpartum period and generally poorer sleep quality than their multiparous counterparts (Signal et Al., 2012). 
Nursing interventions that could improve maternal sleep include sleep hygiene strategies, relaxation techniques, development of appropriate expectations related to maternal and infant sleep, and planning to maximize sleep and rest opportunities (The Open Sleep Journal, 2013), that interventions should reflect multiple influences and provide information, strategies, and encouragement to promote sleep for both mother and infant (Robyn et al., 2006, \& BMJ, 2013) So, the investigator in this study is interesting in assessing the sleeping quality among postpartum women and the effect of the educational intervention about sleeping quality during postpartum women period on their sleeping quality. So, the investigator in this study is interesting in assessing the sleeping quality among first time postpartum women and the effect of the education about sleeping quality during postpartum women period on their sleeping quality.

\section{Significance of the study}

Most women (78\%) report their sleep quality to be worse during the childbearing period than in any other time of their lives (Foundation, 2013), with nulliparas being at higher risk of insufficient sleep than multiparas (Lee, et al., 2013).

Hiscock and Wake's in their randomized cluster trails (RCT) evaluated sleep quality in only the final 57 women enrolled in their study at Morgantown, West Virginia (total $n=156$ ). By using two items from a sleeping quality index PSQI (Pittsburgh Sleep Quality Index,2016), at two months post intervention women in the intervention group were significantly more likely than women in the control group to rate their own sleep quality as "very good" and less likely to rate it as "very bad" (X2=9.93, $\mathrm{p}=0.02$ ) and were more likely to report they had "enough" sleep and less likely to have "not enough sleep" (X2=8.11, p=0.04). PSQI total scores were not reported (Hiscock, et al., 2011).

\section{Aim of the study}

\section{The aim of this study was}

1- To assess the sleeping quality index among postpartum mothers.

2- To determine the impact of educational intervention on improvement of postpartum sleeping pattern alterations.

\section{Subject \& Method}

Research design: This study was Randomized Control Trail.

Setting: This study was conducted at the postpartum ward, of Al-Azhar Assiut University Hospital. It has obstetrics and gynecological wards which provide tertiary maternity care services throughout 24 hours.

\section{Sample}

Participants were 550 postpartum women were recruited for this study. Random assignment was done by computer generated tables. Concealed envelopes containing the random number made to be opened after deciding to include women in the study by sample size calculation was based on the primary outcome measures This was done by using two sided chi- square (X2) test with $\alpha$ of 0.05 , a total sample size of at least 535 women in 2 groups and raised to 550 for accuracy (275 in each arm) will have $95 \%$ power to detect a $10 \%$ difference in the proportion of sleeping pattern (Epi-info, CDC, USA, 2008).

\section{Inclusion criteria}

The study population included all postpartum women with no chronic illness who delivered at Al-Azhar Assiut University Hospital.

\section{Exclusion criteria}

- Women who refused to participate in the study.

- Unavailability of phone number to contact with the woman.

\section{The participants were randomized to \\ Group 1}

The intervention group: it is consisted of 275 postpartum women who were taught about the good sleeping and was receive a booklet that containing sleeping educational intervention about the quality of sleeping pattern as limit drinks with caffeine after 2 p.m., smoking prevention (even passive smoking) which can keep from falling asleep, education about food that can affect sleep, limit the amount and drinks in the evening to decrease the need to wake up to urinate at night, describing the type of food that helps to sleep and promote healthy sleep and daytime alertness, women could try a 'late feed or sleepy feed' at about 10:00pm, before going to bed, and this may help their babies to sleep longer, women should keep themselves healthy, following "sleep hygiene", a warm bath or shower before bed can be helpful, education about sleep hygiene "the healthy habits of good sleep" and daytime alertness, education about how to interpret their babies' needs and respond to them and learn them relaxation and breathing techniques. They received the sleeping education on their first day postpartum at their rooms and followed up by telephone call or by contacting them at the postpartum clinic at the 15 days and at the end of the 6th week postpartum (42 days) to check the sleeping pattern.

\section{Group 2: The control group}

It is consisted of 275 postpartum women who take routine care and was assessed immediately after delivery and another time at the 15 days and after the end of the 6th week postpartum by telephone call or by contacting them at the postpartum clinic. 


\section{Tools of the study}

The tools used for data collection consisted of a structured interviewing questionnaire and follow up sheet that were designed by the researcher and included two tools:

Tool (1): structured interview questionnaire It was designed and utilized by the researcher to collect the required data from every postpartum woman at the selected setting. The questionnaire consisted of the following parts:

\section{Part (1): personal data that included}

Personal data such as: name, age, occupation, address, telephone number, level of education, occupation, type of home and residence.

Part (2): The current delivery outcomes

Obstetrical history which included: Parity, stillbirth, number of living children, outcomes of delivery (spontaneous vaginal delivery, SVD with episiotomy, instrumental delivery, and caesarean section), admission to neonatal intensive care unit, complications during labor, and length of hospital stay before discharge.

Tool (2): Sleep quality index (Pittsburgh Sleep Quality Index, 2016)

The Pittsburgh Sleep Quality Index (PSQI) is a questionnaire that assesses sleep quality over a 1month time interval. The measure consists of 19 individual items, creating 7 components that produce one global score, and takes 5-10 minutes to complete (Buysse, et al., 2016).

Sleep quality index, each item is weighted on a $0-3$ interval scale. The global PSQI score is then calculated by totaling the seven components scores, providing an overall scores ranging from 0 to 21 , where lower scores denote a healthier sleeping quality and this score divided into:

- Good sleep quality (0-7).

- Moderate sleep quality (8-14).

- Poor sleep quality (15-21).

The Pittsburgh Sleep Quality Index, 2016 now is used by researchers working with people from adolescence to late life. The PSQI is recommended in independent reviews because it has accumulated a substantial amount of research evidence. In addition to the measure's promising reliability and validity, its brevity and accessibility as a free measure allows the measure great potential for clinical practice (Pittsburgh Sleep Quality Index, 2016).

\section{Procedure}

The study was carried out during the period from the first of November 2014 to the end of April 2016 (average 2 postpartum women the day). At the first meeting with the women the investigator introduced herself, and explained the nature and aim of the study then obtained participants' oral consent. The researcher interview the women, each interview took about 30 minutes. Every postpartum women interview face to face to assess the sleep quality, on their first day postpartum in their rooms in postpartum ward to complete the questionnaire which including personal data, the current delivery outcomes, Pittsburgh Sleep Quality Index, 2016 (PSQI) questionnaire.

These women were followed up by meeting them at the postpartum outpatient clinic or by contacting their telephone at the 15 days and at the end of the 42 days postpartum. The researcher follow-ups after 15 days and at the end of $6^{\text {th }}$ week postpartum. Both groups were asked about: features of subjective sleep quality, sleep latency, sleep duration, habitual sleep efficiency, usage of sleeping medications, and daytime dysfunction over the last month of their pregnancy.

The study group was provided by sleeping educational intervention in about 30 minutes which covered sleep hygiene, relaxation, and strategies for increasing maternal sleep, parenting and sleep disruption, and details about infant sleep. The researcher explained the optimal sleeping education intervention and provided each woman a booklet containing the sleeping educational intervention with clear, understandable, simple Arabic language.

Follow up at the 15 days and at the end of the $42^{\text {nd }}$ days postpartum

For both groups, the researcher followed up them at the postpartum outpatient clinic or by telephone call at the 15 days and at the end of $6^{\text {th }}$ week postpartum (42 days postpartum) to assess the sleeping quality and the effect of the educational intervention.

\section{Pilot study}

Pilot study will be conducted on the available number of $(10 \%) 50$ of postpartum women in the postpartum period to test the clarity of the question and to detect any further problem or difficulties that help in making the necessary changes in the questionnaire. Women of the pilot study were included in the main sample results.

\section{Statistical analysis}

Data entry and statistical analysis were done using SPSS version 16.0 statistical software package. Data were presented using descriptive statistics in the form of frequencies and percentages for qualitative variables, mean and standard deviation for quantitative variables. Statistical significance was considered at $\mathrm{P}$-value $\leq 0.05$. 


\section{Results}

Table (1): Distribution of the studied women according to their socio-demographic characteristics.

\begin{tabular}{|c|c|c|c|c|c|}
\hline \multirow{2}{*}{ Item } & \multicolumn{2}{|c|}{ Study(N=275) } & \multicolumn{2}{|c|}{ Control (N=275) } & \multirow{2}{*}{ P. Value } \\
\hline & $(N=275)$ & $\%$ & $(\mathrm{~N}=275)$ & $\%$ & \\
\hline Age/years, mean \pm SD & \multicolumn{2}{|c|}{$25.71 \pm 5.55$} & \multicolumn{2}{|c|}{$25.38 \pm 5.4$} & 0.479 \\
\hline \multicolumn{6}{|l|}{ Educational level } \\
\hline Illiterate. & 9 & 3.3 & 4 & 1.5 & \multirow{5}{*}{0.403} \\
\hline Read and write. & 10 & 3.6 & 7 & 2.5 & \\
\hline Primary educational. & 20 & 7.3 & 23 & 8.4 & \\
\hline Secondary educational & 157 & 57.1 & 172 & 62.5 & \\
\hline University educational & 79 & 28.7 & 69 & 25.1 & \\
\hline \multicolumn{6}{|l|}{ Occupation } \\
\hline Employed & 36 & 13.1 & 16 & 5.8 & \multirow{2}{*}{0.061} \\
\hline Housewife & 239 & 86.9 & 259 & 94.2 & \\
\hline \multicolumn{6}{|l|}{ Residence } \\
\hline Rural & 192 & 69.8 & 187 & 68.0 & \multirow{3}{*}{0.147} \\
\hline Semi- urban & 51 & 18.5 & 66 & 24.0 & \\
\hline Urban & 32 & 11.6 & 22 & 8.0 & \\
\hline \multicolumn{6}{|l|}{ Type of home } \\
\hline Independent housing & 177 & 64.4 & 171 & 62.2 & \multirow{2}{*}{0.596} \\
\hline Shared housing & 98 & 35.6 & 104 & 37.8 & \\
\hline \multicolumn{5}{|c|}{ Is there anyone who can help in the care of newborn } & \\
\hline Yes & 185 & 67.3 & 165 & 60.0 & \multirow{2}{*}{0.076} \\
\hline No & 90 & 32.7 & 110 & 40.0 & \\
\hline
\end{tabular}

Table (2): Distribution of the studied women according to their obstetrical history.

\begin{tabular}{|c|c|c|c|c|c|}
\hline \multirow{2}{*}{ Item } & \multicolumn{2}{|c|}{ Study (N=275) } & \multicolumn{2}{|c|}{ Control (N=275) } & \multirow{2}{*}{ P. Value } \\
\hline & $(\mathrm{N}=275)$ & $\%$ & $(\mathrm{~N}=275)$ & $\%$ & \\
\hline \multicolumn{6}{|l|}{ Parity } \\
\hline Primiparous & 130 & 47.3 & 110 & 40.0 & \multirow{2}{*}{0.056} \\
\hline Multiparous & 145 & 52.7 & 165 & 60.0 & \\
\hline \multicolumn{6}{|l|}{ Mode of delivery } \\
\hline Spontaneous vaginal delivery. & 43 & 15.6 & 59 & 21.5 & \multirow{3}{*}{0.116} \\
\hline Vaginal delivery with episiotomy & 79 & 28.7 & 63 & 22.9 & \\
\hline Caesarean section & 153 & 55.6 & 153 & 55.6 & \\
\hline \multicolumn{6}{|l|}{ Complication during labor } \\
\hline None & 265 & 96.4 & 262 & 95.3 & \multirow{4}{*}{0.421} \\
\hline Postpartum hemorrhage & 2 & 0.7 & 4 & 1.5 & \\
\hline Perineal tears & 7 & 2.5 & 5 & 1.8 & \\
\hline Medical complication & 1 & 0.4 & 4 & 1.5 & \\
\hline \multicolumn{6}{|l|}{ Neonatal condition } \\
\hline Living & 274 & 99.6 & 275 & 100.0 & \multirow{2}{*}{0.317} \\
\hline Still birth & 1 & 0.4 & 0 & 0.0 & \\
\hline \multicolumn{6}{|l|}{ Admission to NICU } \\
\hline Yes & 42 & 15.3 & 30 & 10.9 & \multirow{2}{*}{0.129} \\
\hline No & 233 & 84.7 & 245 & 89.1 & \\
\hline No. of children for every mother, mean \pm SD & \multicolumn{2}{|c|}{$2.34 \pm 1.79$} & \multicolumn{2}{|c|}{$2.61 \pm 1.69$} & 0.067 \\
\hline Length of hospital stay / days, mean \pm SD & \multicolumn{2}{|c|}{$1.63 \pm 0.61$} & \multicolumn{2}{|c|}{$1.69 \pm 0.55$} & 0.214 \\
\hline
\end{tabular}




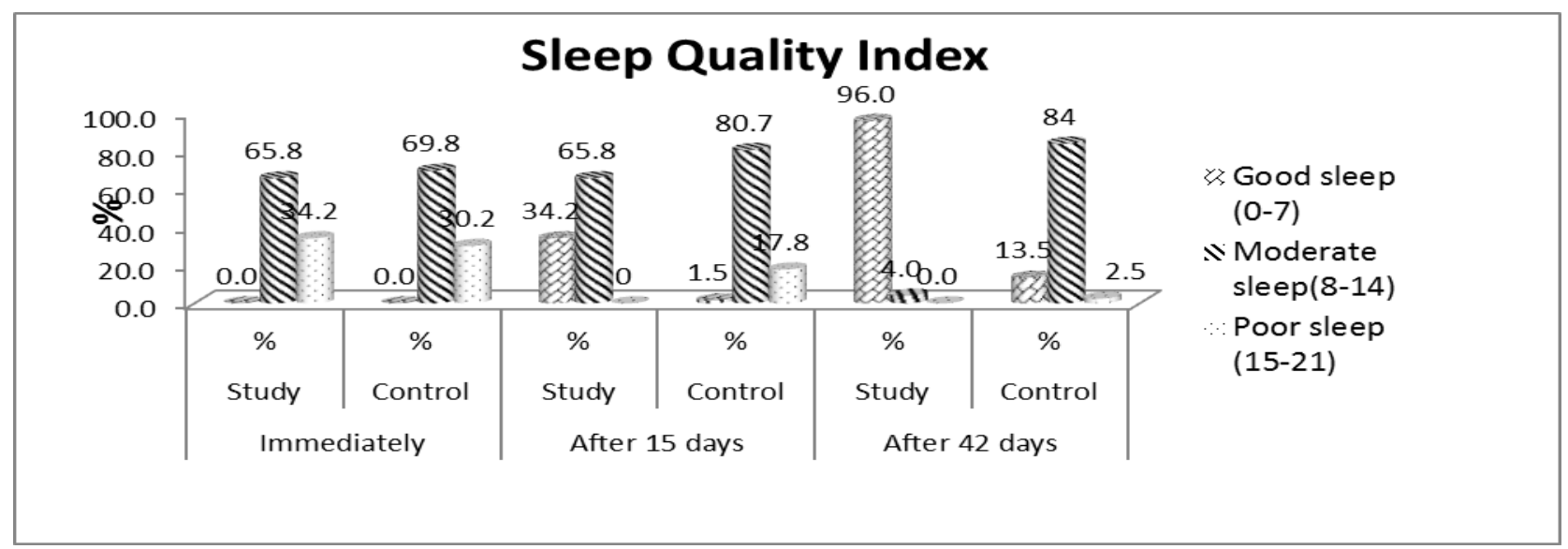

Figure (1): Distribution of the studied women according to their total sleep quality index immediately after delivery, after 15 days and after 42 days postpartum.

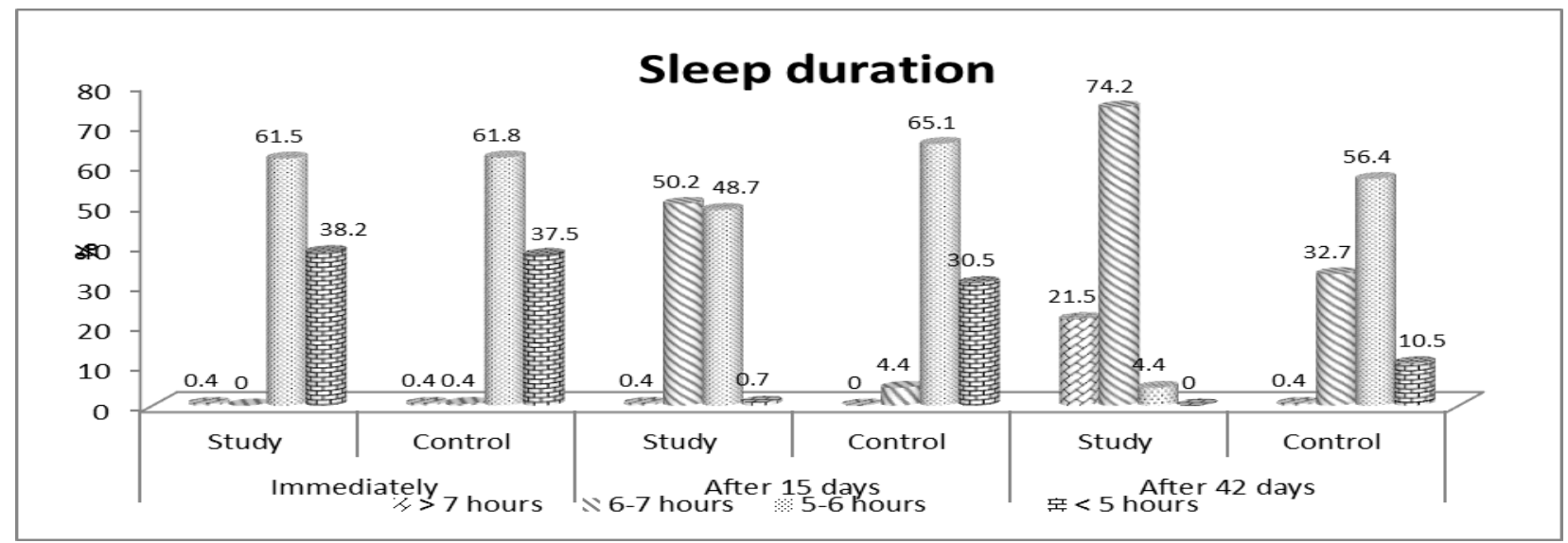

Figure (2): Distribution of the studied women according to their sleep duration immediately after delivery, after 15 days and after $\mathbf{4 2}$ days postpartum women.

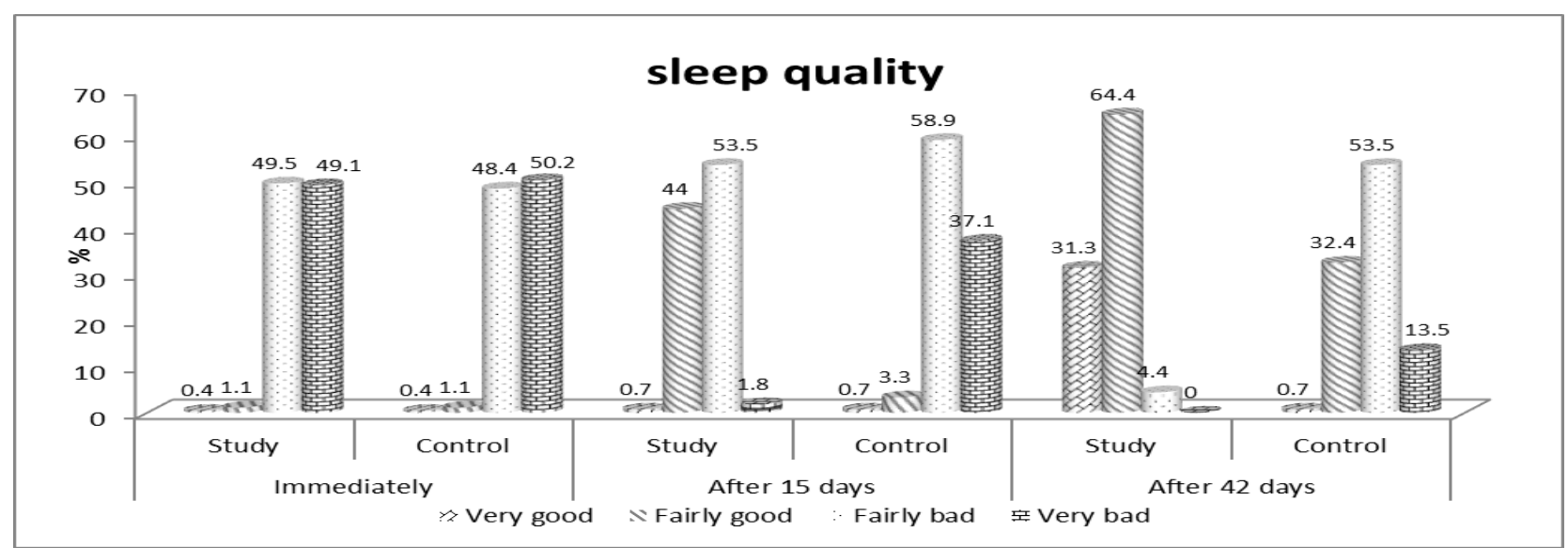

Figure (3): Distribution of the studied women according to their subjective sleep quality immediately after delivery, after 15 days and after $\mathbf{4 2}$ days postpartum. 


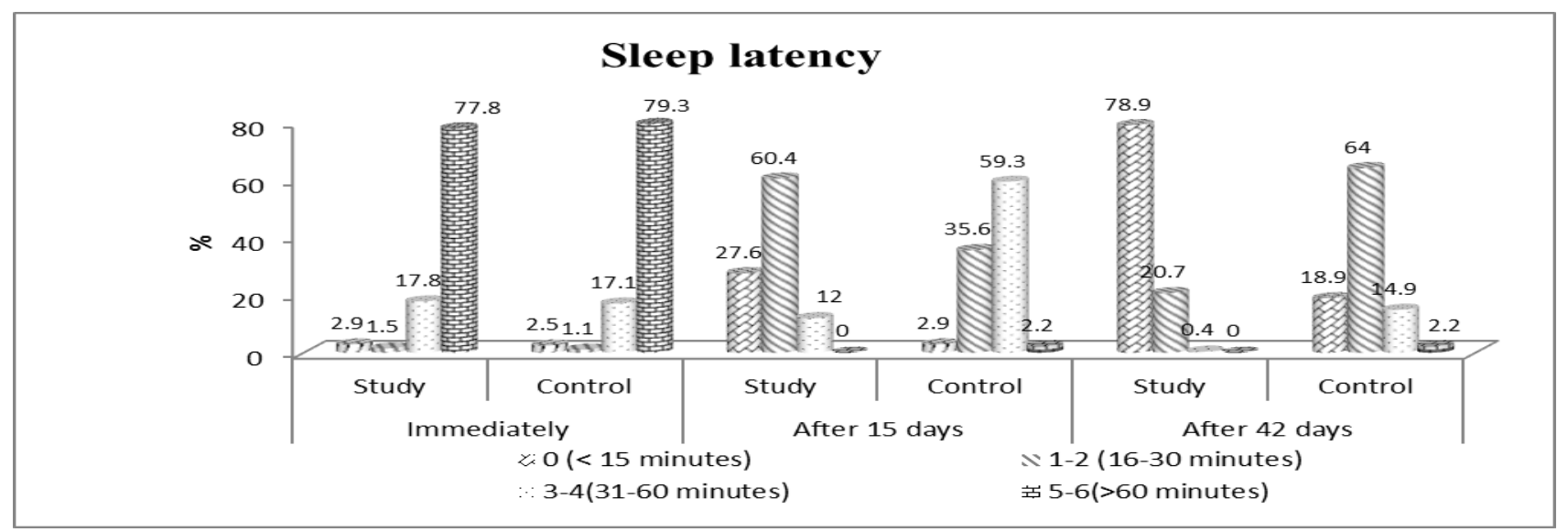

Figure (4): Distribution of the studied women according to their sleep latency immediately after delivery, after 15 days and after 42 days postpartum.

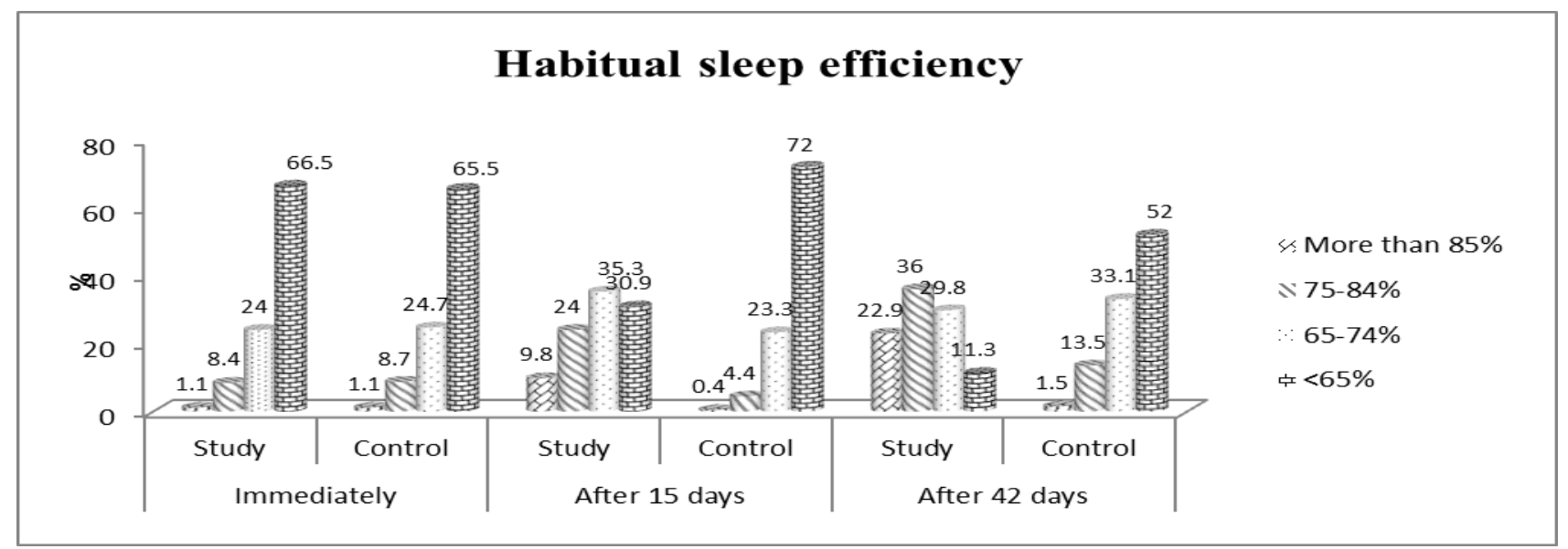

Figure (5): Distribution of the studied women according to their habitual sleep efficiency immediately after delivery, after 15 days and after 42 days postpartum.

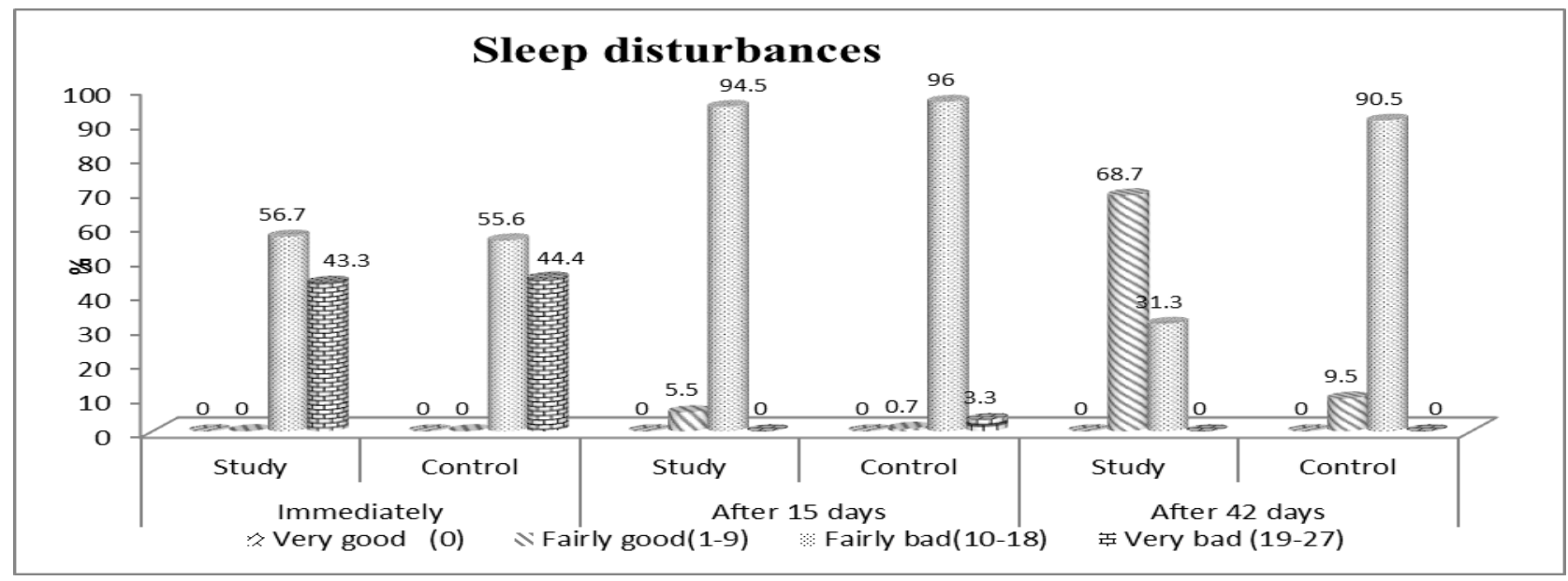

Figure (6): Distribution of the studied women according to their sleep disturbance immediately after delivery, after 15 days and after 42 days postpartum. 


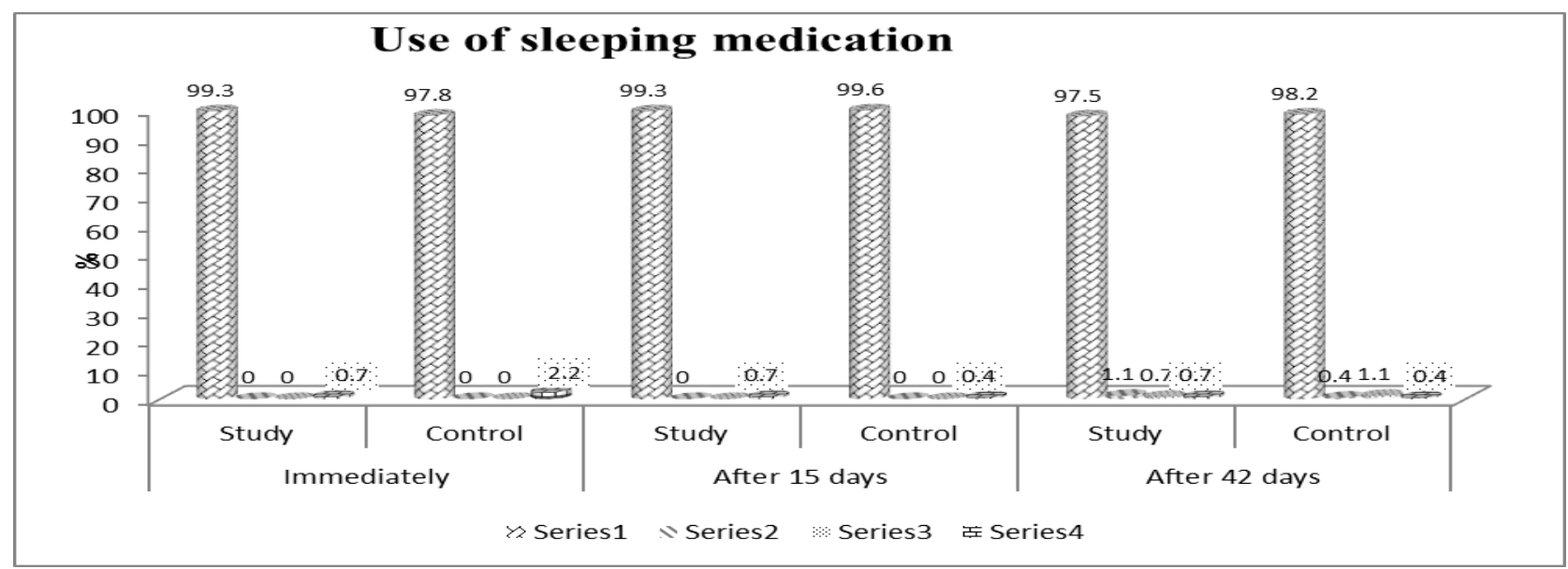

Figure (7): Distribution of the studied women according to their using of sleep medications immediately after delivery, after 15 days and after 42 days postpartum.

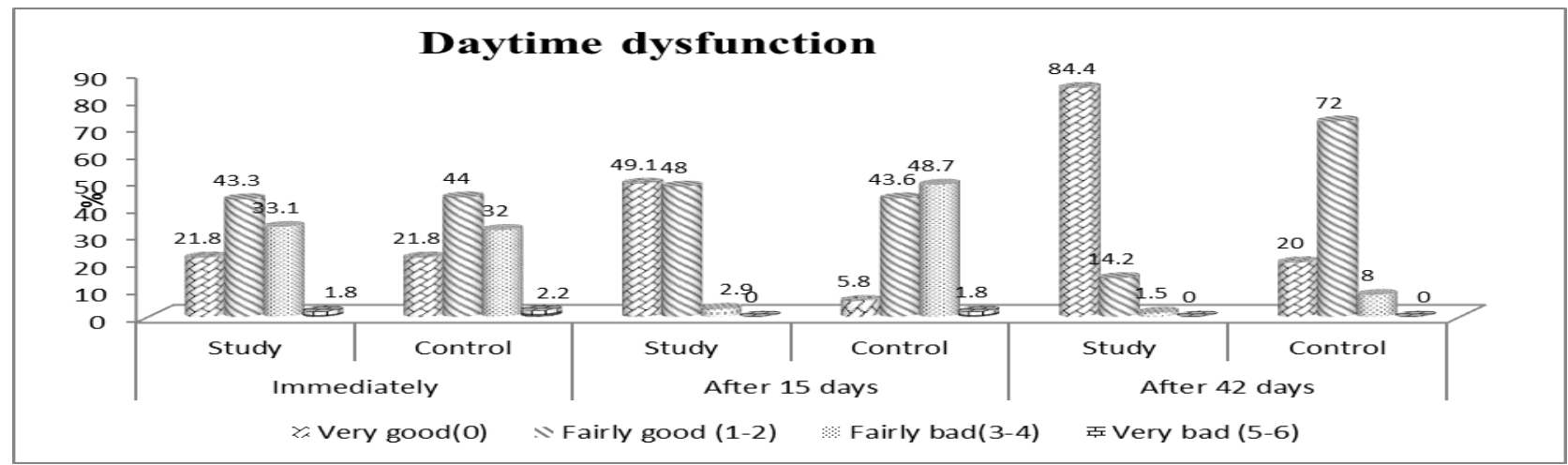

Figure (8): Distribution of the studied women according to their daytime dysfunction immediately after delivery, after 15 days and after 42 days postpartum.

Table (3): Relationship between sleep quality index of the studied groups and their socio demographic characteristics after $\mathbf{4 2}$ days postpartum

\begin{tabular}{|c|c|c|c|c|c|c|c|c|c|c|c|c|c|c|c|}
\hline \multirow{3}{*}{ Item } & \multicolumn{4}{|c|}{ Good sleep Quality } & & \multicolumn{4}{|c|}{ Moderate sleep Quality } & \multirow{3}{*}{ P. value } & \multicolumn{4}{|c|}{ Poor Sleep Quality } & \multirow{3}{*}{ P. value } \\
\hline & \multicolumn{2}{|c|}{ Study } & \multicolumn{2}{|c|}{ Control } & \multirow{2}{*}{ P. value } & \multicolumn{2}{|c|}{ Study } & \multicolumn{2}{|c|}{ Control } & & \multicolumn{2}{|c|}{ Study } & \multicolumn{2}{|c|}{ Control } & \\
\hline & $(\mathrm{N}=264)$ & $\%$ & $(\mathrm{~N}=37)$ & $\%$ & & $(\mathrm{~N}=11)$ & $\%$ & $(\mathrm{~N}=\mathbf{2 3 1})$ & $\%$ & & $(\mathrm{~N}=\mathbf{0 . 0})$ & $\%$ & $(N=7)$ & $\%$ & \\
\hline Age & \multicolumn{2}{|c|}{$25.59 \pm 5.49$} & \multicolumn{2}{|c|}{$25.05 \pm 5.1$} & 0.578 & \multicolumn{2}{|c|}{$28.64 \pm 6.48$} & \multicolumn{2}{|c|}{$25.42 \pm 5.42$} & 0.058 & \multicolumn{2}{|c|}{$25.71 \pm 7.02$} & \multicolumn{2}{|c|}{$0 \pm 0$} & \\
\hline $\begin{array}{l}\text { Educational } \\
\text { level }\end{array}$ & & & & & & & & & & & 0 & 0 & 0 & 0 & - \\
\hline Illiterate. & 9 & 3.4 & 0 & 0.0 & \multirow{5}{*}{0.239} & 0 & 0.0 & 4 & 1.7 & \multirow{5}{*}{0.765} & 0 & 0 & 0 & 0 & \multirow{5}{*}{ - } \\
\hline $\begin{array}{l}\text { Read and } \\
\text { write. }\end{array}$ & 10 & 3.8 & 0 & 0.0 & & 0 & 0.0 & 7 & 3.0 & & 0 & 0 & 0 & 0 & \\
\hline $\begin{array}{l}\text { Primary } \\
\text { educational. }\end{array}$ & 20 & 7.6 & 1 & 2.7 & & 0 & 0.0 & 22 & 9.5 & & 0 & 0 & 0 & 0 & \\
\hline $\begin{array}{l}\text { Secondary } \\
\text { educational }\end{array}$ & 149 & 56.4 & 27 & 73.0 & & 8 & 72.7 & 140 & 60.6 & & 0 & 0 & 5 & 71.4 & \\
\hline $\begin{array}{l}\text { University } \\
\text { educational }\end{array}$ & 76 & 28.8 & 9 & 24.3 & & 3 & 27.3 & 58 & 25.1 & & 0 & 0 & 2 & 28.6 & \\
\hline \multicolumn{16}{|l|}{ Occupation } \\
\hline Employed & 33 & 12.5 & 0 & 0.0 & \multirow{2}{*}{0.023} & 3 & 27.3 & 14 & 6.1 & \multirow{2}{*}{0.007} & 0 & 0 & 0 & 0.0 & \multirow{2}{*}{-} \\
\hline Housewife & 231 & 87.5 & 37 & 100.0 & & 8 & 72.7 & 217 & 93.9 & & 0 & 0 & 7 & 100.0 & \\
\hline
\end{tabular}




\begin{tabular}{|c|c|c|c|c|c|c|c|c|c|c|c|c|c|c|c|}
\hline Residence & & & & & & & & & & & & & & & \\
\hline Rural & 182 & 68.9 & 28 & 75.7 & \multirow{3}{*}{0.483} & 10 & 90.9 & 154 & 66.7 & \multirow{3}{*}{0.234} & 0 & 0 & 5 & 71.4 & \\
\hline Semi- urban & 50 & 18.9 & 4 & 10.8 & & 1 & 9.1 & 60 & 26.0 & & 0 & 0 & 2 & 28.6 & . \\
\hline Urban & 32 & 12.1 & 5 & 13.5 & & 0 & 0.0 & 17 & 7.4 & & 0 & 0 & 0 & 0.0 & \\
\hline \multicolumn{15}{|l|}{$\begin{array}{l}\text { Type of } \\
\text { home }\end{array}$} & \\
\hline $\begin{array}{l}\text { Independent } \\
\text { housing }\end{array}$ & 170 & 64.4 & 27 & 73.0 & \multirow{2}{*}{0.304} & 7 & 63.6 & 139 & 60.2 & \multirow{2}{*}{0.819} & 0 & 0 & 5 & 71.4 & - \\
\hline $\begin{array}{l}\text { Shared } \\
\text { housing }\end{array}$ & 94 & 35.6 & 10 & 27.0 & & 4 & 36.4 & 92 & 39.8 & & 0 & 0 & 2 & 28.6 & \\
\hline \multicolumn{16}{|l|}{$\begin{array}{l}\text { Is there } \\
\text { anyone who } \\
\text { can help in }\end{array}$} \\
\hline Yes & 177 & 67.0 & 23 & 62.2 & \multirow{2}{*}{0.556} & 8 & 72.7 & 129 & 55.8 & \multirow{2}{*}{0.270} & 0 & 0 & 3 & 42.9 & \multirow{2}{*}{ - } \\
\hline No & 87 & 33.0 & 14 & 37.8 & & 3 & 27.3 & 102 & 44.2 & & 0 & 0 & 4 & 57.1 & \\
\hline
\end{tabular}

Table (1): Shows that, there are no statistical significant difference between both groups regarding maternal age, educational level, occupation, residence, and type of home.

Table (2): This figure presents that, there are no statistical significant difference between groups regarding their parity, mode of delivery, complications that occurred during the previous deliveries, condition of the neonates, and the admission of the neonates to newborn intensive care unit (NICU).

Figure (1): Illustrates the distribution of the studied women according to their total sleep quality index immediately after delivery, after 15 days and after 42 days of postpartum women. It shows that, immediately after delivery, about two thirds $(65.8 \%)$ of the study group had moderate sleep quality Vs. $(69.8 \%)$ of the control group with no statistical significant difference between both groups. While women of both groups after 15 days and after 42 days postpartum shows a highly statistical significant difference between them regarding sleep quality index $(\mathrm{P}=0.000)$.

Figure (2): Illustrates that, women of both groups immediately after delivery, had no statistical significant difference regarding the sleep duration that women get at night, while both groups after 15 days postpartum and after 42 days postpartum shows a highly statistical significant difference between control and study groups regarding sleep duration $(\mathrm{p}=0.000)$.

Figure (3): This Figure illustrates the distribution of the studied women according to their subjective sleep quality immediately after delivery, after 15 days and after 42 days of postpartum women, it shows that, immediately after delivery, slightly less than one half (49.5\%)of the study group Vs. (48.4\%) of the control group had fairly bad sleep quality and $49.1 \%$ of the study group Vs. (50.2\%) of the control group had very bad sleep quality with no statistical significant difference between both groups. While women of both groups after 15 days and after 42 days postpartum shows ahighly statistical significant difference between both groups regarding subjective sleep quality $(\mathrm{P}=0.000)$.

Figure (4): Illustrates the distribution of the studied women according to their sleep latency immediately after delivery, after 15 days and after 42 days postpartum. It shows that immediately after delivery, more than three quarters of women of the study group $(77.8 \%)$ had getting sleep within > 60 minutes Vs. $79.3 \%$ of the control group with no statistical significant difference between both groups, while women of both groups after 15 days and after 42 days postpartum showed a highly statistical significant difference between them regarding the sleep latency $(\mathrm{P}=0.000)$.

Figure (5): Illustrates the distribution of the studied women according to their habitual sleep efficiency immediately after delivery, after 15 and 42 days postpartum. It shows that immediately after delivery, more than two thirds of women of the study group $(66.5 \%)$ had getting $<65 \%$ of sleep efficiency Vs. $(65.5 \%)$ of the control group with no statistical significant difference between groups. While women of both groups after 42 days postpartum showed a highly statistical difference regarding habitual sleep efficiency $(\mathrm{P}=0.001)$.

Figure (6): Illustrates the distribution of the studied women according to their sleep disturbance immediately after delivery, after 15 and after 42 days postpartum, it shows that immediately after delivery, more than half of women of the study group (56.7\%) Vs. $(55.6 \%)$ of the control group had getting fairly bad sleep with no statistical significant difference between groups, while women of both groups after15 
days and after 42 days postpartum showed a highly statistical significant difference regarding sleep disturbance.

Figure (7): Illustrates the distribution of the studied women according to their using of sleep medications immediately after delivery, after 15 days and after 42 days postpartum, it shows that immediately at delivery, $(99.3 \%)$ of the study group and $(97.8 \%)$ of the control women didn't use sleeping medication with no statistical difference between both groups, after 15 days of postpartum, women showed a highly statistical difference $(\mathrm{P}=0.000)$ regarding use of medication. While, after 42 days of postpartum, it was observed that studied postpartum women of both group (97.5\%) Vs. (98.2\%) didn't used sleeping medication with no statistical difference between both groups.

Figure (8): Illustrates the distribution of the studied women according to their daytime dysfunction immediately after delivery, after 15 days and after 42 days postpartum. It presents that immediately after delivery, more than one third $(43.3 \%)$ of women of the study group Vs. (44.0\%) of the control group had fairly good daytime dysfunction with no statistical significant difference between both groups. While, women of both groups after 15 days and after 42 days postpartum showed a highly statistical difference regarding daytime dysfunction $(\mathrm{P}=0.000)$.

Table (3): This table shows the relationship between sleep quality index of the studied groups and their socio demographic characteristics at 42 days postpartum. No statistical significant difference was observed as this regards with their age, educational level, occupation, redsidence, type of home and if there is anyone who can helping them in the care of newborn during postpartum period.

\section{Discussion}

Women experience dramatic changes during the postpartum period involving not only hormones and physiology, but also changes in lifestyle, sleep patterns, responsibilities, and interpersonal relationships. All of these changes can influence sleep patterns and sleep quality. Indeed, new mothers generally experience sleep disruptions for up to one year or more (Montgomery-Downs\& Gozal, 2013).

This randomized controlled study aimed to assess the sleeping quality index among postpartum mothers and to determine the impact of educational intervention on improvement of postpartum sleeping pattern alterations.

Results of the present study success to achieve the hypothesis that postpartum women in the intervention group who received the educational intervention about good sleeping had significantly good sleeping quality than those who received the routine postpartum care.

According to the present study inputs, majority of women in the whole sample were housewives and were living in rural areas. Their socio-demographic characteristics and obstetrical data are typical of the women attending university and governmental hospitals and they were matched in the two studied groups with no statistical significant difference. This was beneficial to the present study as it ensured generalization of the study results as well as avoiding the effect of the confounding variables.

Concerning the sleep quality index immediately after delivery, both groups showed no statistical significant difference between them. After 15 days postpartum and following receiving the educational intervention, women of the study group showed a significant improvement of sleep quality as about half of these women reported good sleep quality. These findings are agreed with the results of (Hiscock \& Wake, 2011) who studied the maternity behavioral sleep intervention to improve their sleep and maternal mood. They found that, two months post intervention women in the study group were significantly more likely than the control group to rate their sleep quality as "very good" and less likely to rate it as very bad. Moreover, this finding is also agreed with (Salazaro,2016) who conducted this study to assess the quality of sleep in a pregnant women who underwent prenatal in a health center in Tremenbe city on 30 pregnant women he found that, about two thirds of pregnant women had good sleep quality compared to fewer women who had good sleep quality. These findings can pointed to the most important point in this study when women was previously encouraged to be educated about the changes in sleep quality and how can they be emerged in improving their sleep quality; furthermore, this results alarms us to the role of nursing education in improving women's health specially at this specific point of their postpartum period.

As regards the subjective sleep quality about half of women of the study and control group rated their subjective sleep quality immediately after delivery, to be fairly bad sleep quality and the other half of the studied groups rated their subjective sleep quality as very bad sleep with no statistical significant difference between both groups. While results of both groups after 15 days and after 42 days postpartum show a highly statistical significant difference between both groups regarding subjective sleep quality $(\mathrm{P}=0.000)$. These results come in the same line with the findings of (Razaei et.al, 2014). This study was conducted in Maku city, west Azerbaijan, Iran; They found that about half of their studied women of 
the intervention group had good subjective sleep quality, while about less than one third of the control group had good subjective sleep quality compared to few pregnant women of both groups reported their subective sleep quality to be very good. These results are similar to each inspite of the difference in the study population, this similarity are contributing to the hormonal changes of pregnancy that affects the pregnant women at this period.

Regarding sleep duration which is considered an important measure of normal physiological sleep, the present study presented that; about two thirds of the studied women of the groups had sleep duration from 5-6 hours a day immediately after delivery. Sleep duration was improved to 6-7 hours a day after 15 days of postpartum period among women of the study group in significantly higher percentages than the control group. Moreover, sleep duration was improved after 42 day postpartum among women of the study group as about one fifth of these women slept more than 7 hours a day. These results are in agreement with that of (Rezaei et al., 2014) who studied the effect of sleep health behavioral education on the improvement of sleep duration which improves the depression in pregnant women with sleep disorders. This study was conducted in Maku city, west Azerbaijan, Iran; they found women of the study group showed a mean sleep duration reduced from 7 hrs 16 minutes at week 32 of pregnancy to 6 hrs 31 minutes at week 8 postpartum and increased to 6 hrs. 52 minutes after 2 years of delivery. Because of the importance of the sleeping disturbances in the disorder related to sleep duration due to childbirth, the researcher is interested in highlighting this part of the sleeping disorder. When comparing the present study results with others

Regarding the sleep latency, the present study shows that, immediately after delivery, few women rated their sleep latency score to be $<15$ minutes; meaning that they are falling asleep within $<15$ minutes and had improved after receiving the education 15 and 42 of postpartum period. These results are in the same line with that of (Santigo et al., 2015) to assess sleep disorders in pregnancy who found that slightly less than two fifths of pregnant women of the study group to assess their sleep quality had their sleep latency from 16-30 minutes, while few of them rated their sleep latency score to be zero and most of them were falling asleep within 31-61 minutes.

According to the present study regarding sleep disturbances immediately after delivery, after 15 and after 42 days postpartum, findings shows that immediately after delivery, more than half of women of the both groups had getting fairly bad sleep with no statistical significant difference, while women of both groups after15 days and after 42 days postpartum showed a highly statistical difference regarding sleep disturbance as more than two thirds of the study group their sleep disturbances were improved after 42 days postpartum. The present study results are in agreement with (Rezaei et al, 2014); they showed that about half of the studied mothers had fairly bad quality sleep. Meaning, the studied mothers were disturbed once or twice a week, which is differ from the present study as women reported sleep disorders in the vast majority of the studied women, that was their sleep disturbed twice or more a week, this may be due to Pain or discomfort while trying to sleep, more frequent night-time toilet visits which are common. Many women experienced symptoms of insomnia, whilst some develop restless leg syndrome and/or sleep apnea. Also the most common sleep difficulties during pregnancy are frequent night wakening, difficulty falling asleep and waking too early. On the other hand findings of the present study regarding their sleep disturbances at immediately after delivery were in disagreement with (Santigo, et al., 2015), they reported that more than two thirds of pregnant women during their last month of pregnancy had fairly good sleep and disturbed their sleep less than once a week due to pregnancy changes.

Also the present study reported that more than two thirds of intervention group had fairly good sleep pattern. Meaning; the intervention group was disturbed less than once a week, due to the educational intervention which encourage women to sleep in preference to other activities who change their daily routine, habits and infants make changes in their sleep pattern as they develop. Hence, the sleep disturbance associated with motherhood will improve with time. After 42 days postpartum of postintervention women in the intervention group were significantly more likely than women in the control group to rate their own sleep disturbances as fairly good and less likely to rate it as fairly bad with a highly statistical difference. $(\mathrm{p}=0.004)$. Also this finding was agreed with (Rezaei et al., 2014), they showed that a four-week health behavior education program, improved the sleep quality of participants due to variation of diet and activity, life style that influenced pattern and quality of sleep during pregnancy and postpartum.

According to habitual sleep efficiency immediately after delivery, the present study found few of the studied women had rated their habitual sleep efficiency to be more than $85 \%$, while more than two thirds rated their habitual sleep efficiency to be $<65 \%$. The present study greed with (Rezaei, et al., 2014), they found that about one fifth in study group, and about one sixth of their sample in control group rated their habitual sleep efficiency to be more than 
$85 \%$.Also the present study findings are disagreed with (Santos et al., 2012), who reported that more than two thirds of pregnant women at third trimester had their habitual sleep efficiency $85 \%$ or more than $85 \%$. Furthermore, the present study is agreed with (Sivertsen, et Al., 2015) who studied the sleeping at the third trimester; its physical and impact on women's health, they reported that the majority of the study group rated their habitual sleep efficiency as $83.6 \%$ at 32 weeks of pregnancy and $74.2 \%$ at 8 weeks postpartum. Same results also were reported by (Tomfohr, et al., 2013) who studied the psychomotor characteristics of the Pittsburgh sleep quality index in Mexican.

Concerning to their daytime dysfunction immediately after delivery, after 15 days and after 42 days postpartum, the present study showed that more than two fifths of the studied women had fairly good daytime dysfunction during the day at the last month of pregnancy. This result was agreed with (Teresa Celia et al., 2012), they reported that more than two fifths of studied women had fairly good daytime dysfunction at the last month of pregnancy. This finding was agreed the results of (Rezaei et al., 2015), they showed that about one fifth of the study group and more than one third of control group had fairly good day time dysfunction during the day and had some sort of malfunction.

After 42 day of the postpartum period, the majority of the study group had very good sleep quality with no daytime dysfunction; versus one fifth of control group had very good sleep quality with no daytime dysfunction. And this finding was disagreed with (Sivertsen et al., 2015), they reported that sleep dissatisfaction and daytime impairment significantly more commonly reported during pregnancy 32 weeks of pregnancy compared to 8 weeks postpartum, whereas difficulties maintaining sleep was significantly more common at 8 weeks of postpartum compared to 32 weeks of pregnancy.

Concerning to the use of sleeping medications, the present study findings show that, vast majority of studied women didn't use sleeping medications, while few of them use sleeping medications three or more times a week at the last month of pregnancy. After 42 days postpartum, few of women of the intervention group use sleeping medications less than once a week postpartum. The present study findings agreed with that of (Rezaei et al., 2014), they found all of the studied women didn't use sleeping medications that considered zero in final score calculation at the last month of pregnancy and following the childbirth.

The present study showed the effect of the education intervention on the improvement of the seven components of the sleep quality index ( subjective sleep quality, sleep latency, sleep duration, habitual sleep efficiency, sleep disturbances, use of sleeping medication, and daytime dysfunction) at the postpartum period.

\section{Conclusion}

Based on the present study findings, it was concluded that most of the participants women experiencing disturbed sleeping quality during last month of pregnancy and postpartum period. After implementing the educational intervention, maternal sleep quality, subjective sleep quality, sleep duration, sleep latency, habitual sleep efficiency, sleep disturbances, use of sleep medication and daytime dysfunction were improved after 15 and 42 day of postpartum period, with a highly statistical significant difference between groups.

\section{Recommendations}

\section{Based on the results of this study it was} recommended that

I. Further efforts are needed through educational intervention programs by nurses to improve maternal sleeping quality during pregnancy and the postpartum period.

II. Special attention is needed by health care providers for pregnant mothers in discussing sleep habits and healthy sleep hygiene.

III. More researchers are needed to improve newborn sleep quality and pattern to improve maternal sleep quality and sleep pattern.

\section{References}

1. The Open Sleep Journal, (2013): Postpartum Sleep in New Mothers and Fathers.

2. Journal of nursing, quality of sleep in pregnant women, (2012): Apr, 839-846.

3. Tomfohr, L., Schweizer, C., Dimsdale, J.,\& Loredo, J., (2013): "Psychometric characteristics of the Pittsburgh Sleep Quality Index in English speaking non-Hispanic whites and English and Spanish speaking Hispanics of Mexican descent.". Journal of Clinical Sleep Medicine. 9 (1): $\quad$ 61-6. Doi: 10.5664/jcsm.2342. PMID 23319906.

4. BMJ (2013): 346:f1164 doi: 10.1136/bmj.f1164, Page 1 of 14, Effect of behavioural-educational intervention on sleep for primiparous women and their infants in early postpartum: multisite randomized controlled trial (Published 20 March 2013).

5. Rezaei E., Moghadam Z., Nejat S., \& Dehgannayeri N., (2014): impact of sleep healthy behavior education on the quality of life in the pregnant women with sleep disorder: A 
randomized control trial. Irania $\mathrm{J}$ of $\mathrm{Ng} \&$ Midwifery, Sep. 19(5)508-516.

6. Thomas K., \& Foreman S., (2013): Infant sleep and feeding pattern: effects on maternal sleep. J Midwifery and Women's Health; 50:399-404.

7. Waters, M., \& Lee, K., (2012): Differences between primigravidae and multigravidae mothers in sleep disturbances, fatigue, and functional status. J Nurs Midwifery.; 41(5):364-367. Doi: 10.1016/S0091-2182(96).

8. Karacan I., Williams R., Hursch C., McCaulley M., Heine M., (2013): Some implications of the sleep patterns of pregnancy for postpartum emotional disturbances. $\mathrm{Br}$ J Psychiatry; 115:929-35.

9. Kathryn A., Lee, Mary Ellen Zaffke, \& Geoffry Mcenany (2010): The Department Of Family Health Care Nursing, School Of Nursing, University Of California, San Francisco, San Francisco, California.. Parity and Sleep Patterns During And After Pregnancy.Vol. 95, No. 1.

10. Manber R., Steidtmann D., Chambers A., Ganger W., Horwitz S., Connelly C., (2013): Factors associated with clinically significant insomnia among pregnant low-income Latinas. J Womens Health (Larchmt) Aug; 22(8):694-701.

11. Sivertsen B., Lallukka T., Salo P., Pallesen S., Hysing M., \& Krokstad S., (2015): Trajectories of maternal sleep problems before and after childbirth. Results from the large populationbased prospective HUNT study in Norway. J Sleep Res. 2015; 23:124-32

12. Thomas K., \& Foreman S., (2013): Infant sleep and feeding pattern: effects on maternal sleep. J Midwifery and Women's Health; 50:399-404.

13. Buysse, Daniel J., Reynolds, Charles F., Monk, Timothy H., Berman, Susan R., Kupfer, \& David J., (2016): "The Pittsburgh sleep quality index: A new instrument for psychiatric practice and research". Psychiatry Research. 28 (2): 193 213.doi:10.1016/0165-1781(89)90047-4.

14. Epi-info ${ }^{\text {TM }}$, CDC, USA, (2008).

15. Gay C., Lee K., \& Lee S., (2012): Sleep patterns and fatigue in new mothers and fathers. Biol Res Nurs, 5(4):311-318.

16. Goyal D., Gay C.,\& Lee K., (2012): Patterns of sleep disruption and depressive symptoms in new mothers. J Perinat Neonatal Nurs.; 21(2):123129.

17. Hiscock H., \& Wake M., (2011): Randomised controlled trial of behavioural infant sleep intervention to improve infant sleep and maternal mood. BMJ; 324: 1062-65.

18. Instruments: Pittsburgh Sleep Quality Index (PSQI)"(2016): University of Pittsburgh Sleep
Medicine Institute. University of Pittsburgh. Retrieved 16 September.

19. Lee K., (2016): Alterations in sleep during pregnancy and postpartum. Sleep Med Rev 2016; 2:231-242.

20. Lee K., \& Gay C., (2013): Sleep in late pregnancy predicts length of labor and type of delivery. Am J ObstetGynecol Dec; 191(6):20416.

21. Manber R., \& Armitage R., (2013): Sex, steroids, and sleep: A review. Sleep 2013; 22: 540-55.

22. Mollayeva, T., Thurairajah, P., Burton, K., Mollayeva, S., Shapiro, C., \& Colantonio, A., (2015): "The Pittsburgh sleep quality index as a screening tool for sleep dysfunction in clinical and non-clinical samples: A systematic review and meta-analysis." Sleep medicine reviews. Doi:10.1016/j.smrv.01.009. PMID 26163 057.

23. Montgomery-Downs H., \& Gozal D., (2013): Prevalence and risk factors for snoring from birth to two years. Sleep Med; 7: 211-9.

24. Robyn Stremler, R., Ellen Hodnett, R., Kathryn Lee, R., Shauna Macmillan, R., Catriona Mill, R., Lisa Ongcangco, R., Andrew Willan, (2013): A Behavioral-Educational Intervention to Promote Maternal and Infant Sleep: Pilot Randomized, Controlled Trial.

25. Salazaro P., (2016): Long lasting disturbances in women after childbirth. J Reprod Infant Psychol; 5:245-246.

26. Santiago J., Nolledo M., Kinzler W., Santiago T., (2015): Sleep and sleep disorders in pregnancy. Ann Intern Med. Feb;13;134(5):396408.

27.Signal T., Gander P., \& Sangalli M., (2012): Sleep duration and quality in healthy nulliparous and multiparous women across pregnancy and post-partum.Aust $\mathrm{N} \quad \mathrm{Z} \quad \mathrm{J}$ ObstetGynaecol , 47(1):16-22.

28. Teresa Celia de Mattos Moraes dos Santos, Ana Lucia De Faria, Milva Maria Figueiredo De Martino, Patrícia Cristina Alves, Pâmela Cristine de Carvalho, (2012): Quality Of Sleep In Pregnant Women, 2012 April, 839-845.

29. Foundation N., (2013): Sleep and women poll http://wwwsleepfoundationorg; accessed March 2013.

30. Robert Rosenberg (2014): DO: 8 Solutions to Your Pregnancy Sleep Problems Last Updated: 11/25/2014;

http://www.everydayhealth.com/columns/robertrosenberg-sleep-answers/solutions-yourpregnancy-sleep-problems. 